\title{
Conhecimento e aprendizado cooperativo na inclusão
}

\section{Knowledge and cooperative learning in the inclusion process}

\author{
Paulo Ricardo Ross*
}

\begin{abstract}
RESUMO
Propõe-se, aqui, analisar possíveis implicações do princípio da diversidade humana aplicado à pedagogia da inclusão das pessoas com necessidades especiais na escola especial e serviços comuns da sociedade. Para tanto, são analisadas as características do conhecimento, dos sujeitos e das interações, nos dias atuais. Apontam-se alguns limites da chamada Sociedade Inclusiva e, ao mesmo tempo, fornecem-se indicações para quem se interesse em contribuir com a organização de práticas cooperativas e valorizadoras das diferenças e das possibilidades.

Palavras-chave: diversidade, aprendizagem cooperativa, inclusão e formação de professores.
\end{abstract}

\begin{abstract}
This work intends to analyse the implications of the human diversity principle referred to as inclusive pedagogy. The goal is to analyse new requirements of people with disabilities in special schools and other spaces and services. We analyse some characteristics of the knowledge, workers and interactions seen nowadays. We mention here some limits of the inclusive society, and at the same time we point out strategies to organize inclusive classrooms. The purpose of these strategies is to develop individual possibilities and differences.

Key-words: diversity, cooperative-learning, inclusion, teacher training.

* Professor do Setor de Educação, graduação e pós-graduação da Universidade Federal do Paraná. Doutor em Educação pela USP e pesquisador em práticas pedagógicas inclusivas.
\end{abstract} pross@uol.com.br. 


\section{Conhecimento e aprendizado cooperativo na inclusão}

Os alunos com necessidades especiais não podem mais permanecer isolados no trabalho de sala de aula, tampouco serem exigidos por meio de desempenhos que enfatizem competências ou habilidades mentais centradas na acumulação de conteúdos. Esses alunos serão tanto mais humanizados e independentes, quanto mais compartilharem de atividades em equipe, nas quais possam manifestar sua aprendizagem, seus talentos e, por conseqüência, suas diferenças. A manifestação ou a garantia da heterogeneidade lhes confere o direito de pertencer, de participar, de constituirem-se como humanos, e de não serem rejeitados, pois a padronização das respostas humanas não pode mais ser exigida.

Este artigo é relevante porque estão em discussão as políticas de inclusão social das pessoas que apresentam necessidades especiais. A partir de 1995 vem sendo discutido no Brasil o processo de inclusão das pessoas com necessidades especiais, preferencialmente na rede regular de ensino. Pretende contribuir para a formação da pedagogia da diversidade que supere as práticas tradicionais de ensino-aprendizagem que vêm sendo levadas a cabo tanto pelos profissionais das salas de recursos quanto por aqueles das salas comuns.

Parte-se do pressuposto que as pessoas são resultados de suas relações sociais e, portanto, suas dificuldades não resultam unicamente das deficiências biológicas que possam apresentar. Do mesmo modo, suas necessidades especiais são decorrentes das oportunidades existentes ou não, bem como dos instrumentos e mediações que possam ser apropriados por estas pessoas em suas relações sociais.

A opção metodológica referida não pretende emocionalizar, mas propor alternativas para o atual processo de educação inclusiva do qual participam alunos com necessidades especiais, discutindo idéias que fundamentem situações educadoras que valorizem as diferenças e possibilidades de cada um.

Partindo do pressuposto de que a prática social não é determinada por relações de consangüinidade, isto é, que não são inatas, pode-se afirmar que são as leis da complementaridade que determinam as relações entre os seres humanos. "Aquilo que sei fazer só adquire valor na relação com o outro, quer para complementar habilidades, quer para transformar concepções equivocadas ou distorcidas sobre algo" (ROSs, 1998).

Pretende-se que as relações continuem sendo regidas pela capacidade humana de prever os resultados do seu trabalho, estabelecer intencionalidades, antecipar e organizar os meios e os instrumentos para produzir este trabalho. 
Essa capacidade não inclui a rigidez centrada na estabilidade e na burocracia dos planejamentos, mas a flexibilidade que abriga as adaptações do mundo para acolher as pessoas. Essa capacidade abre-se para o novo conhecimento, para os novos sujeitos, para as novas possibilidades de aprender e de fazer.

Esse novo conhecimento não pretende separar, hierarquizar e classificar pessoas e papéis, mas impulsionar interações, de tal modo que as diferenças e possibilidades de cada um se manifestem. Aceitar as diferenças não significa revestir o trabalho de docilidade ou de irracionalidade, mas significa aprender com a riqueza dos encontros e das interações entre pessoas. Aceitar as diferenças não comporta a imposição unilateral da vontade nem da razão, mas significa a habilidade de pôr em movimento os talentos de cada um em favor do seu grupo, do trabalho do grupo, que é sinergético, em favor de cada um.

O novo conhecimento não é universal, imutável, tampouco centrado somente no sujeito. Só pode ser expresso nas suas possibilidades de estabelecer cadeias, ramificações, não está num produto único, num produto material. Está no mapa das relações, nas múltiplas interações possíveis no quanto cada sujeito pode ser sensibilizado por outro. Este novo conhecimento trata da possibilidade de aprender a aprender, sendo sujeito e sendo produto, ao mesmo tempo, das relações.

Esse novo conhecimento científico responde a uma necessidade histórica concreta e real de transformação. $\mathrm{O}$ superdesenvolvimento das tecnologias permite-nos vislumbrar o esgotamento de clássicas contradições e fragmentações, nas quais a opressão, a desigualdade, a ignorância, a miséria, a marginalização, o fatalismo, a inevitabilidade da ordem estabelecida, a segregação e a rotulação de pessoas como incapazes eram exigências estruturais e ideológicas da sociedade industrial. Mas as novas possibilidades históricas permitem que se organizem processos de ensino-aprendizagem menos para a repetição linear do que é ensinado e mais para a criação; menos para a transmissão unilateral de saberes acumulados e mais para estabelecer análises, reflexões à luz do contexto social em que se vive.

O conhecimento necessário é menos resultado de lecionação e mais resultado do trabalho de co-gestão das pessoas engajadas. Esse conhecimento dá lugar a menos polarizações e hierarquizações e mais interatividade, mais complementaridade e mais diferença. Essa nova materialidade histórica exige novas proclamações de direitos, como as de menos exclusão, menos pauperização e mais responsabilidade social, menos dominação e mais ofertas de ajuda, menos desigualdades e mais organismos e instrumentos de resgate da dignidade humana. 


\section{Necessidades para uma pedagogia da inclusão}

A necessidade dos vínculos nos remete à Pedagogia do Pertencer: sem a ressonância positiva daquilo que fazemos não nos sentimos suficientemente alimentados para prosseguir a caminhada. "Se as impossibilidades forem maiores do que as possibilidades, eis que uma cortina de incapacidade me revestirá e todo meu ser será escondido, anulado. Então, eu serei um anormal, um deficiente, um ser inferior. Passarei a entender que não posso aprender." Se o pensamento e a prática de professores se centrarem nos limites, nas dificuldades do sujeito que aprende, de nada adiantará estudar as teorias inatistas e ambientalistas. Tudo concorrerá para o imobilismo ou para a espontaneidade, para a permanência, para as visões estáticas. "Nada em mim se modifica, nenhuma função, nenhum comportamento novo, nenhuma habilidade pode ser adquirida." Isto anuncia que tudo está no lugar ou tudo está fora do lugar, tudo é normal ou tudo é anormal. Internamente, as respostas teriam limites bem definidos, compatíveis às funções biológicas aparentes ou manifestas.

Externamente, não haveria nada o que fazer. A prefixação, o fatalismo, a naturalização das desigualdades podem justificar as incapacidades, as limitações e a inferioridade das pessoas com deficiência.

Porém, só pode haver desenvolvimento e aprendizagem se o outro nos propiciar experiências positivas. O caráter positivo de nossas experiências é a marca vital de nosso pertencimento. Não há pertencimento sem a formação de vínculos sociais com a família, com a escola e com a cultura a qual ajudamos a construir.

A necessidade da auto-aceitação nos remete à Pedagogia do Autoconhecimento. $\mathrm{O}$ "conhece-te a ti mesmo" não é um simples exercício de introspecção, identificando limites ou virtudes individuais, talentos ou habilidades inatos. A pedagogia do autoconhecimento busca pôr em movimento os produtos histórico-culturais em favor de cada um. Trata-se de avaliar a qualidade das oportunidades sociais propiciadas para cada um. Somos o resultado dessas experiências sociais.

Aceitação não é resignar-se com as dificuldades imediatas, mas localizar alternativas que favoreçam as mudanças. "Só posso me tornar confiante quando as condições externas se modificam paralelamente às conquistas que me são permitidas avançar."

A necessidade do outro faz nascer a pedagogia do acolhimento. $\mathrm{O}$ império da razão forjou um ser humano individualista, centralizador e supostamente capaz de criar grupos sociais homogêneos, normais, produtivos, com 
papéis e funções divididos e encadeados entre si. A negação da pessoa com deficiência era uma exigência, pois não se podiam afirmar as próprias deficiências daquela sociedade. A perfeição bio-físico-sensorial era a norma funcional e produtiva. Na sociedade industrial, imperava a rotina de tarefas, de tempos e de movimentos. O trabalho físico separado do trabalho mental era a norma. $\mathrm{O}$ enquadramento, a classificação e a rotulação eram a norma éticopolítica de base econômica.

Porém, numa sociedade democrática pós-industrial, as pessoas não podem mais ser vistas como massa, na qual todos são iguais. Trata-se, agora, de defender e satisfazer as necessidades segundo o seu tipo, grau e natureza.

Por meio das estratégias de cooperação torna-se mais clara nossa contribuição em educar para conviver com o outro. É preciso ser alguém no mundo e ser alguém para alguém. Ao invés de adversários, como se proclamava na sociedade industrial, somos todos diversidades; ao invés de exercermos funções no mundo, interagimos em relações heterogêneas. É preciso que razão e sensibilidade nos movam para o outro não exatamente para reproduzir uma ordem ou regra estabelecida, mas para impulsionar-lhe o passo, a manifestação, a participação e a criação. Se as diferenças são as marcas fundamentais das relações sociais, significa o rompimento de toda espécie de rótulos e preconceitos. Nesta perspectiva, ninguém pode ser chamado de diferente, porque a diferença irá manifestar-se em novas individualidades dos novos sujeitos ou atores sociais. Na verdade, a individualidade das pessoas que apresentem necessidades especiais só será produzida quando estiverem conquistadas as condições para estabelecer com autonomia, independência e apoio suas relações sociais. A conquista da individualidade é a expressão maior da diferença que se pretende que seja a marca da sociedade. Proclama-se que não haja necessidade de nenhum qualificativo para designar este ou aquele indivíduo. As designações classificatórias ao outro dão lugar ao respeito à individualidade que se caracteriza na forma da tolerância. Na perspectiva de uma sociedade inclusiva, a tolerância deixa de ser característica das pessoas consideradas altruístas ou solidárias, passando a ser uma exigência de um comportamento que já estará inscrito na individualidade de cada um.

O aprender tem uma dimensão individual que se processa coletivamente. O sujeito só aprende na relação com o outro. A aprendizagem é sempre mediada por instrumentos, signos e procedimentos que possibilitam relações entre os sujeitos e objetos e entre os sujeitos. E por que apenas lecionamos como se todos fossem iguais? E por que queremos que repitam as mesmas respostas como quem não conhece as vantagens humanas e pedagógicas das diferenças? 
Todo indivíduo pode dar sua participação e contribuir com sua experiência acumulada e seu poder de decisão, uma vez que o especialista não pode ser mais o portador de todas as verdades. Toda manifestação deverá ser respeitada.

Ora, olhemos para a história para lembrar que as teorias eugenistas e fatalistas raciais ou genealógicas caíram definitivamente com os avanços da ciência em bioquímica, genética, clínica médica, obstetrícia, psicologia do desenvolvimento, puericultura, etc. O psicodiagnóstico da deficiência mental invalidou sua concepção unitária, apontando diferenças qualitativas, graus e áreas de comprometimento, níveis de recuperabilidade e intervenção, proposições de estimulação precoce e reabilitação. Novas entidades clínicas foram descritas e programas terapêuticos instituídos nas áreas de audiologia, foniatria, neurologia e psiquiatria infantil, que em diversos momentos agruparam condições ou respostas fisiológicas como deficiência mental. Foram descobertas possibilidades de prevenção da deficiência mental, aconselhamento genético e dietas apropriadas à recuperação de distúrbios metabólicos. A pedagogia desenvolveu teorias educacionais capazes de operar com o desenvolvimento da inteligência e inúmeras técnicas especiais de educação. A assistência social, a terapia ocupacional, a fisioterapia e a educação física passaram a ampliar a convivência com as pessoas com deficiência mental, propondo técnicas, eventos, movimentos de solidariedade e congraçamento. (СЕCCIM, 1997, p. 39-40).

No século XX, as experiências pedagógicas já realizadas por Pestalozzi (1746-1827), Froebel (1782-1852), Itard (1774-1838), Seguin (1812-1880) e Borneville (seguidor de Seguin), Binet (1905), Maria Montessori (1870-1922) e Decroly (1871-1922) fundamentam uma tendência que comprova a necessidade de resgatar a Educação Especial do domínio estritamente médico. A construção de um campo de responsabilidades, fundamentos e idéias relativos a essa área de desenvolvimento humano produz como conseqüência mais imediata o incremento de programas educativos para os alunos com necessidades especiais, porém considerados como uma entidade à parte do sistema educativo geral.

Marca-se, então, o surgimento da Educação Especial fundamentalmente a partir das contribuições desses autores. Esses estudos mostraram a relação existente entre o tipo de inteligência, o grau de capacidades e habilidades com os tipos de experiência ambientais a que o indivíduo foi submetido. Esses resultados conduziram ao questionamento da noção estabelecida da inteligência e do próprio ser humano como algo fixo e predeterminado hereditariamente. O sujeito é educável. E os limites de seus progressos dependerão do 
quantum de inteligência, do grau de comprometimento de funções orgânicas relevantes para a instrução pretendida e da perícia na aplicação do método.

Fundamentalmente, a aprendizagem dependerá das experiências sociais oportunizadas, dos vínculos e desafios oferecidos, das interações e mediações organizadas.

Em conseqüência dessa conquista histórica, questiona-se a legitimidade de empregar rótulos e/ou categorias para descrever e/ou classificar os sujeitos resultantes da aplicação massiva dos testes de inteligência. Considerase que rótulos como atraso mental, distúrbios de aprendizagem e emocionais produzem efeitos negativos, tanto no autoconceito como nas expectativas da sociedade sobre esses sujeitos, as quais contribuem para perpetuar os estereótipos e para obstaculizar a aceitação plena das diferenças individuais (ILLAN, 1992, p. 17-25).

Questionam-se os testes de inteligência não só como origem da rotulação, mas também suas graves consequiências no processo de decisão sobre o encaminhamento de alunos para a Educação Especial como situação duradoura e irreversível.

Nas décadas de 60, 70 e 80, os progressos em neuropsicologia substituem os rótulos qualitativos (idiota, imbecil, débil) ou quantitativos (QI 0-20, 20-50, 50-75, por exemplo) e a psicopedagogia propôs critérios de avaliação e classificação baseados em desempenhos observados nas diversas situações. Mais recentemente, a psicanálise vem contribuindo à produção de relações familiares e sociais capazes de qualificar a deficiência no campo das diversidades humanas, propondo um sistema de estimulação de bebês e produção de vínculos de saúde nas relações familiares e sociais. (CECCIM, 1997, p. 40).

A constatação de uma distinção deveria, sim, contribuir para o desenvolvimento de uma intervenção educativa adequada. $\mathrm{O}$ diagnóstico de necessidades especiais - ao contrário do rótulo - não possui o caráter estático e irremovível; ele converte-se em ponto de partida para a melhoria das possibilidades do indivíduo. 


\section{O conhecimento da modernidade e a era da diversidade}

No fim da década de 60, a partir dos trabalhos realizados por Dunn (apud ILlAN, 1992, p. 25), acentua-se a polêmica entre os defensores da Educação Especial segregada e aqueles que levantam suas inconveniências no momento de recorrer ao sistema educativo regular.

Embora a escola especial e a escola comum tenham construído caminhos paralelos e separados, o caráter seletivo de ambas as instituições pode ser considerado traço comum. A escola comum tradicional exercia essencialmente a função de selecionar aqueles que eram capazes de responder adequadamente às necessidades sociais produzidas em cada contexto social, econômico e político. De outro lado, a instituição especial ocupava-se da função segregadora daqueles considerados menos capazes, os quais deveriam se submeter a atendimentos especializados.

A segregação como estratégia para a escolarização básica destas pessoas seguia os requisitos do modelo clínico centrado no déficit, tendo sido predominante em toda a modernidade até a segunda metade do século passado. Tal modelo se centrava em uma concepção inatista e estática do ser humano, segundo a qual não havia uma expectativa educativa para aqueles que apresentassem déficits, carências ou limitações de ordem biológica-físico-sensorial. Desde a Idade Média a deficiência vem sendo tomada como elemento retardador da ordem social. Neste século, o advento das técnicas psicométricas vem reforçar o caráter estático e classificatório com respeito aos indivíduos que apresentam tais diferenças.

A superação dos modelos segregacionistas inicia-se com a construção teórica, que ao invés de enfatizar os fatores natos deixa de considerar os déficits como estáveis ao longo do tempo e passa a tomá-los a partir das necessidades circunstanciais geradas nas diferentes relações sociais produzidas pelos sujeitos. Essa pedagogia histórico-crítica põe ênfase aos processos de aprendizagem sobre o processo de desenvolvimento. As situações de aprendizagem passam também a constituir-se como critério de avaliação da deficiência. As exigências cada vez maiores por interação escolar destas pessoas produzem modificações na capacitação dos professores e na organização escolar, naquelas instituições regulares que têm de enfrentar o ensino de todos aqueles que vêm recorrendo a elas. Os modelos segregacionistas são postos em xeque à medida em que as causas do fracasso escolar passam a ser localizadas fundamentalmente em fatores sociais, culturais e pedagógicos, contribuindo para o repensar das fronteiras entre normalidade e deficiência, prestando-se, do mesmo modo, ao questionamento dos limites da escola comum e especial. 
No momento em que a própria escola especial faz-se objeto de avaliação, sendo-lhe exigido apresentar resultados quanto à integração social e laboral de seus alunos, entram em crise suas funções e objetivos e o próprio modelo de educação segregada. A constituição do modelo de educação integrada, ao se concentrar nas necessidades educacionais que os alunos possam apresentar em determinados momentos e não nos déficits ou características diferenciais, passa a ser orientada por uma concepção não inatista, mais dinâmica de homem e de educação.

Contudo, a crítica ao modelo especializado de atendimento, somada às pressões sociais e políticas, resulta na formulação de princípios que vão se disseminando por todas as regiões a partir dos anos 60. Pretende-se que a escolarização de todos os alunos, realizada integralmente nas mesmas instituições escolares, seja uma questão de cidadania e não resultado de boas intenções ou de atos samaritanos. Proclama-se que o déficit possa ter sua origem na estimulação ambiental e no próprio processo de aprendizagem e não necessariamente na herança ou estrutura genéticas dos indivíduos. Com a proliferação destes princípios, incorporam-se à educação destas pessoas os conceitos de adaptação social e dificuldades de aprendizagem. A partir dos anos 70, rompe-se a crise dos modelos segregacionistas, firmando-se com cada vez mais força o modelo da integração educacional das pessoas com deficiência.

O conceito de necessidades educacionais especiais desloca o ponto de referência para as possibilidades de escolarização apresentadas por suas características diferenciais e necessidades específicas dos alunos e a capacidade de dar respostas educativas apresentadas pela escola.

Esses avanços desarmaram os argumentos demográficos e seu apelo eugenista de eliminação, esterilização e reclusão das pessoas com deficiência mental, mas não foram suficientes para a libertação da deficiência de sua marca metafísica de maldição ou castigo do céu, nem do fatalismo clínico da hereditariedade inevitável, nem da segregação na educação especial.

Ainda que se pregue, hoje, a exigência por libertar-lhes do cárcere da segregação ou da reclusão, mantém-se o cárcere às suas atitudes e decisões. O destino que lhes é reservado é o de serem pacatos.

Diz a crença construída ao longo da história que para sermos uma sociedade faz-se necessário um conjunto de instituições; regulamentos; leis; postulados médicos; filosóficos; religiosos etc., (que estatuem dispositivos de seleção entre normais e anormais) (СЕCCIM, 1997, p. 43). 
É a vigilância da ordem que aniquila a diversidade em sua existência. Essa ordem, materializada pelo direito positivo, é sustentada pelo domínio da linguagem por parte dos seres racionais que rotulam o outro, a diferença e, ao fazê-lo, o exclui.

... a diversidade inspira ameaça porque confere poder, e aqueles que a sociedade designa como marginais são muitas vezes mantidos à margem justamente porque, no momento certo, a presença deles será necessária no palco. Porter destaca, dentre os marginais, um certo tipo de doido; o bobo: Zumbis inofensivos de miolo mole, normais o suficiente para comunicarem-se, anormais o suficiente para espantar, ofendendo e dizendo o que os outros não podem dizer, esses 'bobos' eram capazes de conseguir aceitação, até mesmo profissão e privilégios, numa sociedade que dificilmente ouvia os loucos como tais (СЕCCIM, 1997, p. 44).

A rejeição às pessoas com deficiência era tida como uma forma de defender a sociedade, os poderes políticos instituídos, valendo-se dos institutos da disciplina, ordem, norma positiva e hierarquia. A ciência médica serviu historicamente para sancionar os poderes socialmente instituídos, prescrevendo aos idiotas e imbecis a prisão domiciliar. "O discurso da medicina, fazendo a mediação entre a soberania e a disciplina, teve na deficiência mental a expressão do furor normalizador." (CECCIM, 1997, p. 46).

A medicina deveria medicalizar todos os comportamentos e desejos. Outras ciências ganharam forças e talvez tenham suplantado a hegemonia da medicina, ainda que não tenham superado o estigma da segregação.

Apesar de tudo isso, a presença da psicanálise veio contrariar a medicina presa ao biológico, à degenerescência, à eugenia e à hereditariedade. A psicologia veio insistir numa etiologia psicogenética da deficiência que consistia na defasagem entre a maturação ontogenética e exposição à experiência ou ao treino. A pedagogia veio explicitar que a ação didática e as atitudes educativas são cruciais na formação de atitudes socioculturais. (CECCIM, 1997, p. 46). 
Nascem os fundamentos científicos de que se necessitam para começarse a acreditar que essas pessoas sejam capazes de aprender, ensinar e romper a barreira da recusa da escuta, fronteira esta que não podiam transpor. Ser capturada e alojada em espaços onde se possa exercer vigilância e dominação tem sido a sina, a marca e a tragédia da pessoa com deficiência.

Contudo, com o advento da ideologia da sociedade inclusiva tem-se um retorno da apologia da comunidade, da cooperação, do comprometimento com o outro, com a qualidade do que se aprende, difundindo-se o restabelecimento de laços entre as pessoas tão longinquamente esquecidas.

Hoje, a desigualdade passa a ser plenamente justificada a partir das diferenças que caracterizam os seres humanos como indivíduos. Argumenta-se que todos têm o direito de pertencer à sociedade, em razão de suas diferenças serem naturalmente herdadas. Contudo, conforme HовBEs (1979, p. 104), "não há paz sem sujeição". Pretende-se que as normas emanadas dos poderes instituídos sejam revestidas de legitimidade, validade e coerência em todo o território junto a todos os cidadãos.

A luta pela integração dos sujeitos com necessidades especiais, suas instituições e suas utopias era expressão de um momento da politização dos sujeitos, de um lado, e a adoção ou implementação de políticas públicas de bem-estar, de outro. Ao se despolitizar constata-se a desintegração das pessoas. Ao invés de se lutar pelo direito ao exercício do trabalho, ao bem-estar, a participação política, a felicidade, a rebeldia, as trocas simbólicas e culturais, é preciso, agora, estar "incluso" simplesmente no processo.

No tempo da desintegração, o tempo atual, as diferenças não necessitam ser superadas, mas simplesmente respeitadas. Esses sujeitos e instituições não são santificados nem inocentes, em função de receberem rótulos como especiais ou diferentes. Suas práticas sociais são interessadas, isto é, atravessadas pela subjetividade que luta por transformações de suas condições sociais de vida.

Por sofrerem um processo de isolamento e segregação social forçado e por terem a subjetividade negada, muitas dessas pessoas que apresentem necessidades especiais não se agregam, de fato, à população brasileira nem sequer ilicitamente.

Se as organizações sociais e a escola conseguirem resgatar a função social e política da educação, uma de suas funções prementes é a de identificar esses milhares de excluídos, recuperando-lhes a identidade, a subjetividade e contribuindo para que superem sua clandestinidade. Contudo, não basta recuperar a individualidade no plano simbólico, mas fazê-lo igualmente nos planos material e político-social. Não basta identificar as deficiências, mas cria- 
rem-se meios de estancar a produção acelerada da deficiência, produto mórbido dos acidentes de trabalho e acidentes de trânsito. Para este produto não há forma nem marketing, mas o descaso. Há uma guerra civil que é incompatível com qualquer projeto de uma sociedade inclusiva, cuja vida possa festejar todos os dias. Ocorre que certas organizações sociais, em razão de sua desintegração e despolitização, formalismo e segmentação, estão limitadas e movidas pela quotidianidade na qual os problemas sociais não entram na pauta de discussões. Em última instância, a problemática da exclusão social e da própria clandestinidade fica restrita à preocupação dos próprios excluídos.

Tendo-se como pressuposto que os direitos históricos nascem de certas circunstâncias caracterizadas por lutas e defesas contra velhos poderes, resistências e preconceitos ou velhas circunstâncias limitadoras, é neste sentido que se pode dizer irreversível e irresistível o movimento da sociedade inclusiva, a sociedade para todos. Esta sociedade será, irreversivelmente e cada vez mais, adaptada às condições de vida das pessoas dotadas de uma condição biológico-físico-sensorial distinta. As necessidades especiais humanas serão cada vez mais respeitadas na forma de oferecimento das condições específicas para a manifestação humana do direito de educar-se e ser feliz em sociedade.

Assim como a liberdade religiosa é resultante de guerras de religiões, as liberdades civis resultam de povos e parlamentos contra o poder absoluto dos soberanos. Como as liberdades políticas e sociais resultam do fortalecimento das lutas dos trabalhadores, dos sem-terra, as liberdades pessoais das pessoas com deficiência nascem do reconhecimento social geral como seres individuais dignos da condição humana. Do mesmo modo que os trabalhadores exigem dos poderes públicos a proteção do trabalho contra o desemprego, a gratuidade e qualidade dos serviços educacionais, as pessoas com deficiência exigem a proteção às suas necessidades específicas, condição essencial à manifestação do respeito às suas diferenças. Do mesmo modo que as pesquisas biológicas produziram condições para que indivíduos reclamem o direito de manipulação ou comercialização de seu patrimônio genético, tais avanços científicos produzem as possibilidades de que determinadas pessoas passem a ter o direito de ampliar suas funções biológico-orgânicas, repercutindo diretamente em sua qualidade de vida.

Toda vez que uma gama de direitos se apresenta como possível, em determinada sociedade, ainda que se constitua em base material para novas reivindicações, representa socialmente a forma mais desenvolvida, tornando praticamente inadmissíveis formas retrógradas de vida. No momento em que a pessoa considerada deficiente passa a existir concretamente, interagindo 
com outros, assumindo responsabilidades, desenvolvendo capacidades, revelando talentos na realização de diferentes trabalhos, seus direitos passam a existir como decorrência de sua condição de agente único e ao mesmo tempo coletivo, distinto e integrado nas relações sociais. Os direitos são expressões materiais da existência social dos homens. Se não for dado ao ser humano o direito de interagir socialmente frente às diversidades, não se produzirá nele os benefícios resultantes das lutas e resistências, porque não terá lutado na vida real.

Em condição segregada, haverá a representação de um pseudomundo, maquiando a própria máscara de persona. E a máscara é um instrumento de alimentação do imaginário, mas, ao mesmo tempo, falseia minhas reais necessidades. Nesse sentido, pode-se afirmar que o ser humano só se faz pessoa ou persona na vida real, a vida pública. É no teatro da vida pública em que assumimos os diferentes papéis como personagens e atores de nossa existência. Nos ambientes segregados e restritos, o ser humano manifesta apenas suas necessidades primárias e privadas. Quanto mais se consolida a vida na sociedade das pessoas anteriormente marginalizadas, mais se denunciam suas necessidades e, ao mesmo tempo, mais se assumem como fundamentais, inalienáveis e invioláveis os direitos à vida, à liberdade, ao pensamento e expressão, direito à educação, ao trabalho, enfim, à constituição da individualidade no seio das relações sociais. É a vida em sociedade que materializa as formas de viver: é fundamental o direito à educação, dar e receber apoio, transformar conceitos, procedimentos e sentimentos estabelecidos; é a vida em sociedade que desenvolve estratégias práticas de superação das limitações humanas.

Neste sentido, há que se superar as representações sociais da deficiência, caracterizadas pelas idéias de inferioridade, protecionismo, piedade, genialidade e, ao mesmo tempo, certas proclamações constantes de declarações políticas da "igualdade de oportunidades", tendo em vista a necessidade de se compreender o homem ativo, suas lutas reais para superar as dificuldades e apropriar-se tanto da sua individualidade como dos bens socialmente construídos. 


\section{Para compreender a inclusão}

A aprendizagem sempre esteve atrelada aos paradigmas ora idealistas, ora empiristas, que determinaram diferentes concepções de educação e diferentes estratégias pedagógicas e diferentes formas de organização da escola. As visões empiristas sobre aprendizagem negaram todo o percurso trilhado pelos alunos nos dias e anos anteriores ao período escolar. As experiências produzidas, as necessidades, as aspirações não eram levadas em conta para efeito da organização dos programas escolares e das aulas. Importava acumular dados, acrescentar fatos, conteúdos, reunir quantidades externas e transferir para as bases cognitivas internas dos alunos. Essa perspectiva, também chamada de ambientalista na Psicologia, podia ser equiparada à produção em massa na sociedade industrial, cujas quantidades precisavam ser estocadas para atender às demandas futuras já previstas e pré-estabelecidas. As demandas não eram alteradas, assim como os saberes acumulados podiam ser sempre os mesmos, imutáveis e estáveis. Esperava-se que todos repetissem quando solicitados aquelas lições teóricas supostamente aprendidas na escola.

Este era, pois, o aprender valorizado na escola. Este era, pois, o aprender transmitido. Este deveria ser, pois, o aprender repetido pelos alunos. Em outros períodos históricos, contudo, outro paradigma se protagonizava e se fazia hegemônico nas concepções pedagógicas. Tratava-se do inatismo, fundado na matriz do idealismo. O saber estava lá dentro do aluno pronto, bastando ser desabrochado na forma de idéias, atitudes, capacidades e criatividade. $\mathrm{O}$ mundo estava pronto para ser descoberto por parte de cada um. Era preciso, então, descobrir, construir, potencializar aquela essência presente intrinsecamente em cada um. Todos eram dotados de dons, talentos, vocações, aptidões e bastava algum esforço para que viessem à tona.

Mas o aprender não pode limitar-se a essas visões polarizadas, ora centradas no professor como agente transmissor, ora centradas no aluno como aquele que descobre o conhecimento.

O professor não pode aparecer como genitor, aquele que faz nascer o conhecimento, pois sabe-se que não resulta dele ou não está nele sua origem, tampouco é o professor o detentor dos instrumentos para sua criação. Sempre que essa idéia constituiu-se como hegemônica, parece que tanto o professor como o aluno não eram concebidos como agentes de sua história e de suas relações, posto que não se produzia a interatividade, mas tão-somente obediência, subserviência, aniquilamento, morte de um e de outro. Sempre que isto ocorreu ou ocorre, a capacidade criadora dá lugar às habilidades cognitivas 
de memorização centradas na repetição. Era preciso ou ainda é preciso repetir para dar continuidade às verdades produzidas e pré-estabelecidas. Esta era, pois, a condição para que algumas pessoas viessem a assumir funções e papéis bem definidos e bem delimitados na divisão social do trabalho.

A superação dessa visão só é possível quando tornamos explícita a idéia de que quando algo é conhecido não resulta de um criador. Portanto, o professor não é aquele que faz nascer o conhecimento, mas aquele que pode organizar os caminhos, os instrumentos para conhecer, para aprender. O professor é aquele que amplia os braços mentais dos alunos e de si próprio para que ambos se apropriem, compreendam não apenas o já conhecido, mas aquilo que precisa ser conhecido em face das necessidades do contexto social de cada época. $\mathrm{O}$ ensinar e o aprender passam a ser aquele conjunto que alavanca $\mathrm{o}$ processo de compreensão e apropriação, de descoberta e de contextualização. Ao fazer-se como ponte, como mediação, o ensino desconstitui-se como transmissão externa do professor aos alunos.

O ensino, na perspectiva da transmissão, adquire forças de máximas universais, exigindo dos seus participantes a concentração absoluta no conteúdo que é transmitido, visando a sua assimilação e repetição. A atenção centrada somente no objeto que o transmissor manipula fragmenta e divide a atividade mental daquele que se constitui como depositário desse objeto. Neste caso, o aluno não reconhece o ser humano que se apresenta como transmissor, tampouco reconhece o conjunto dos seres humanos que se constituíram historicamente como produtores daquele conhecimento. O conhecimento, nesta perspectiva, passa a constituir-se como objeto morto, e os sujeitos da relação de ensino-aprendizagem, do mesmo modo, passam a ser desconsiderados. Perdem sua história. Perdem sua condição humana. De humanos, passam à condição de autômatos. A capacidade de criar dá lugar à necessidade de reproduzir. Professor e alunos não se sentem como pertencentes à história, mas como meros expectadores daqueles de quem é cobrada a perpetuação de uma história na qual eles não se vêem como sujeitos. O aprender passa a ser resultado de uma atitude contemplativa do conhecimento. As leis rígidas, imutáveis e invariáveis do conhecimento devem reger as ações de alunos e de professores.

Contudo, no outro extremo, apresenta-se outro paradigma da aprendizagem: aquela na qual o aluno aprende por si próprio, por meio de seu próprio comportamento. E, nela, os impactos são igualmente perversos na medida em que se desloca para a pessoa do aluno a responsabilidade de gerar, descobrir por si só, a partir dos seus recursos biológicos e psicológicos e cognitivos, o conhecimento do qual irá se apossar. Os defensores desta visão apontam para 
a possibilidade da conquista da autonomia de cada um, bastando, para tal, o método da autodeterminação, a meritocracia, o esforço individual. Mais recentemente, esta visão agregou os argumentos relacionados ao desenvolvimento de competências, à capacidade de iniciativa, de tomar decisões, fazer escolhas, conferindo à educação um caráter competitivo e mercadológico.

A aprendizagem, como construção do conhecimento, pressupõe entendêla tanto como produto quanto como processo. Assim, não importa apenas a quantidade de conteúdo, mas a capacidade de pensar, interagir, aquilo que é capaz de fazer, interpretar, compreender. A qualidade do conhecimento ligase à possibilidade de continuar aprendendo. Assim, quando o aluno aprende, não se deve levar em conta apenas o conteúdo do conhecimento, mas também como se organiza e atua para aprender.

Desse modo, os alunos se mostram ativos aprendizes quando demonstram a capacidade de selecionar informações relevantes e expressam a organização coerente dessas informações em situações reais, tanto na defesa de um argumento quanto na solução de um problema matemático, identificando os elementos principais e a relação entre eles.

Esse aluno consegue integrar o conhecimento a outros conhecimentos que possui que lhe parecem familiares. Essa capacidade pode ser demonstrada na realização de perguntas, de observações, como proceder para fazer algum tipo de contagem, algum tipo de leitura, ou como transpor determinados obstáculos ou desafios.

Esse aluno realiza procedimentos com uma forte atenção ao processo, verificando tudo aquilo que não se ajusta à idéia inicial, demonstrando um grande poder de revisão e de interpretação para obter o êxito em determinada ação. Trata-se da capacidade de rever decisões tomadas ou planejamentos estabelecidos. Este aluno está fortemente ligado à equipe a que pertence, pois é capaz de perguntar ao outro ou pedir ajuda a alguém que tenha demonstrado conhecer mais sobre um determinado assunto, encorajando-o para guiá-lo ou para atuar como modelo naquela situação. Esse aluno utiliza este processo para analisar novas situações parecidas.

Esses alunos demonstram tolerância, acolhimento e capacidade reflexiva e apreciação da diversidade se, ao observarem uma briga entre os colegas, interrogam-se sobre suas razões, pedem opinião dos adultos ou de outros colegas sobre o que consideram certo ou errado. Demonstram forte senso ético e de justiça. Tomam as respostas dos colegas em relação ao que pensam. Essas pessoas conseguem identificar diferenças entre essa situação e outras já vividas anteriormente, permitindo-lhes raciocinar por comparação, chegando a um juízo de valor, a uma compreensão e a ponderações. 
Os alunos demonstram capacidade de observação e abstração quando estabelecem relações entre diversos objetos, identificam semelhanças e diferenças com base em critérios objetivos e éticos.

Trata-se de uma atividade mental intensa a qual lhes permite obter uma representação individual de conteúdo social. Ler, contar, pular, relacionar-se com o outro sem a mediação da violência, classificar, etc. Do mesmo modo, pode-se afirmar que o conhecimento é produzido mediante um processo de elaboração pessoal, isto é, ninguém pode realizar em seu lugar. Assim, são os alunos os únicos que podem responder por aquilo que conseguiram realizar ou não. São os únicos que podem marcar o conteúdo de significado, a aprendizagem. Dependendo do nível de desenvolvimento dos alunos, as atividades podem ser de caráter manipulativo, sensorial-perceptivo ou físico-motor. Podem recortar, pular, colocar pedras em potes de tamanhos diferentes, sustentar corretamente os potes, identificar dimensões espaciais, dentro e fora, elaborar uma representação intuitiva de volume ou de quantidade.

Mas a atividade fundamental é aquela de identificar aspectos relevantes, reelaborá-los com outras linguagens, forjar imaginações, ações e interpretálas adequadamente. $\mathrm{O}$ desenvolvimento dessas capacidades dependerá dos objetivos do professor, dos conhecimentos prévios dos alunos e das ajudas que recebam no processo de elaboração. O que é objeto de aprendizagem dos alunos são conhecimentos de natureza cultural, os quais devem ser objeto de planejamento para o ensino. Assim, pode-se dizer que a atividade do aluno é social e culturalmente mediada.

Seguem aqui algumas questões que constituem os verdadeiros princípios de uma prática psicopedagógica humanizadora: 1- Você esclarece termos, conceitos e objetivos das tarefas a serem realizadas? 2- Você organiza práticas que permitam a cada um manifestar sua aprendizagem, suas diferenças, seus talentos, suas preferências, conhecimentos anteriores, sua história individual? 3- Você utiliza-se do princípio da intencionalidade e da reciprocidade para valorizar cada pequena aprendizagem, cada avanço conseguido? Manifesta atenção, emoção e propõe outras alternativas de trabalho? 4- Você identifica talentos em cada um dos alunos e organiza estratégias de trabalho interdependente que valorizem esses talentos? 5- Você torna habitual a exploração por parte de cada um dos alunos de outras matérias, ambientes, imagens, outras linguagens, outras formas de pensar, de resolver determinadas questões? 6- Você propicia momentos de interações entre os colegas, com outros profissionais? 7- Você prevê momentos para criatividade, para fantasia, imaginação se manifestarem pedagogicamente na forma de música, desenho, dança, jogo, brincadeira, texto, atitude de servir a alguém ou de agrade- 
cer ajudas recebidas ou aprendizagens conseguidas? 8- Você estimula o raciocínio reflexivo e não simplesmente repetitivo, visando à abstração, à contextualização e à compreensão do sentido do que se aprende e do que se produz?

Indico alguns procedimentos a serem observados pelo professor e por quem pretenda valorizar cada pessoa em suas possibilidades e em suas interações. 1. Especificar claramente os objetivos da lição, com palavras, imagens, sinais e ações. Estimular os alunos a organizar objetivos para o trabalho e para cada um. 2. Tomar decisões para colocar os alunos em grupos de ensino de tal modo a garantir a heterogeneidade. É comum pretender as mesmas respostas, os mesmos desempenhos dos alunos. As diferenças não podem ser respeitadas apenas ao final do trabalho. Elas precisam ser preservadas já no plano das estratégias. Tanto o professor pode prever as diferenças na organização da aula, quanto o aluno pode manifestar suas dificuldades e facilidades antecipadamente, sem medo de fracassar ou de ser rotulado por conta de sua contribuição no diagnóstico de seus limites e possibilidades. 3. Especificar qual atividade de ensino se espera dos alunos e como a interdependência deve ser demonstrada. Por mais simples que sejam as tarefas, as pessoas precisam ter claro o que se espera delas. Esta clareza é parte de um trabalho bem dirigido e com forte senso de justiça, de humanização e de progresso. A tarefa individual sempre tem conexão com o trabalho anterior, ou paralelo, ou posterior de um colega. Não basta compreender essa relação, mas é preciso realizála. 4. Controlar a eficiência das interações cooperativas e intervir para proporcionar assistência à tarefa. Ainda que previstas, as interações podem não acontecer. A intervenção do professor estimula o trabalho e o redireciona, se for necessário. 5. Responder perguntas e ensinar habilidades relacionadas ao trabalho. Toda manifestação é uma hipótese válida para o pensamento e para a ação. 6. Avaliar as realizações dos alunos e a eficiência do grupo. 7. Adaptar a exigência da lição a cada aluno. Não se trata de separar o simples do complexo. Todo conhecimento é complexo. A demonstração individual pode ser menos complexa ou mais complexa, mas a grupal é simplesmente complexa. É preciso encorajar as crianças e jovens a conhecer e apreciar as possibilidades de aprender do outro. A tarefa pode ser subdividida em partes menores. A aprendizagem pode ser mediada por outro colega. 


\section{Um exemplo de inclusão}

Segue aqui um exemplo maravilhoso de "o que" e "como" o professor pode agir para contribuir para uma aula verdadeiramente inclusiva. Em resumo, é muito simples fazer inclusão, mas não é fácil. Requer planejamento e aceitar as diferentes formas de os alunos se expressarem.

$\mathrm{O}$ ensino interativo é centrado na multiplicidade, na variedade e na riqueza de nossos talentos e linguagens. Viva o ensino interativo. A diferença não pode ser apenas discurso! A diferença pode ser vivida, festejada!

É preciso que nós, os professores, comecemos a escrever mais nossas experiências, nossas estratégias, nossas saídas, nossas problematizações diante dos temas e questões que escolhemos para trabalhar o conhecimento. É preciso abandonar o Professor lecionador que existe em nós! Ao falarmos demais, deixamos obscurecer nossas ações. Calamos nossas ações. Escurecemos o sentido de nossas aprendizagens, a riqueza de nossas vivências. Se apenas falamos ou transmitimos o ensino, menosprezamos o tempo do outro. Já é hora de pôr em prática a valorização das múltiplas capacidades, isto é, as capacidades cognitivas, as sociais e pessoais. Imaginação e arte, musicalidade e dança, texto oral e escrito, teatro e mímica, jogos e jograis, desenhos e maquetes, aprendizagens mediadas e independentes, toda essa variedade precisa compor a pedagogia das pessoas, porque assim somos, assim queremos ser!

O professor pode planejar sua aula inclusiva valendo-se menos do livro texto e mais de situações/problema, aprendizado cooperativo, complexo temático, pensamento crítico e estético, valorização autêntica das pessoas e de seus potenciais. Numa aula da quarta série do Ensino Fundamental, os alunos se organizam em equipes, com o critério de se manter a heterogeneidade. A partir do tema água, por exemplo, os desafios são propostos, um para cada equipe, a saber: elaborar problemas sobre volume em diferentes caixas redondas, quadradas, planas, inclinadas; leitura sobre atual estado das águas próprias para o consumo humano; escrever uma carta reivindicando melhorias na estação de tratamento; compor uma paródia sobre a utilidade da água em nossa vida; demonstrar o relativismo dos conceitos de frio, morno e quente; planejar uma visita a um lago da cidade; planejar pesquisas cooperativas sobre o tema água; construir diagramas e murais sobre o consumo e economia de água. Esse trabalho interativo inclui leitura, escrita, dança, imaginação, canto, poesia, desenho, visitas, resolução de problemas, cálculos, decisões teóricas e práticas. Nessas atividades interativas e divertidas, os desafios são 
em diferentes áreas, disciplinas, linguagens, estágios, diferentes complexidades e graus de autonomia. O menino diagnosticado de deficiência mental pode, com ajuda, recortar ou desenhar e, ainda, colar a figura da nuvem ou demonstrála no momento da apresentação, com independência.

Assim, enquanto um grupo está realizando entrevista e desenvolvendo habilidade de ouvir, transcrever, parafrasear e fazer perguntas, outros estão moldando num mural ou em maquete o curso de um dos rios da cidade, após terem feito observações, cálculos de escalas, cortes, colagens e moldagens de materiais. Nessa pedagogia, os estudantes trabalham juntos e ensinam uns aos outros. São co-gestores. Planejam e vivem o que aprendem.

O Paradigma da Inclusão requer que apoiemos os professores para ensinar interativamente, em complexidade, em rede e não em série, em separado, em compartimentos sem sentido. A Inclusão é verbo e não substantivo.

\section{Conclusões}

Numa era do trabalho centrado nas pessoas, como a que vivemos, a escola não pode escapar deste propósito maior: ou forma as pessoas para relacionar-se umas com as outras, ou continuará a contribuir para a desigualdade social, não fornecendo instrumento nenhum de luta pela cidadania. A escola diz ensinar, enquanto os alunos insistem em demonstrar que não aprendem nada das lições escolares. Já as experiências produzidas em outras lutas, em outros enfrentamentos, como a busca pelo trabalho, as resistências para aquisição do saber para realizar o trabalho, as humilhações pela falta de comida ou de dinheiro ou de argumento, estas não só calam fundo nas pessoas, mas ensinam muito, porque aprender é estar frente a frente com situações reais, ainda que já tenham sido vividas por muitas gerações passadas.

Nos ambientes ditos inclusivos é preciso predominar a aprendizagem mais cooperativa, mais desafiadora e menos competitiva. Para tal, o professor precisa ser menos lecionador e mais gestor do conhecimento, de estratégias de aprendizagem, de desafios e das diferenças entre pessoas.

As interações e experiências necessitam ser positivas. Os alunos podem aprender a ser ouvintes ativos, a fazer perguntas e a responder às necessidades dos outros. Isto pode ser um passo para a maior aceitação dos colegas. Ambientes, profissionais, currículos e conhecimentos que pretendam ser verdadeiramente humanizadores caracterizam-se por: 
- Compartilhar em aula talentos, experiências, e preferências de cada um; assumir o ponto de vista dos outros; comprometer-se nas escolhas de atividades; ouvir as idéias e as necessidades das pessoas e colocar-se na posição do outro. - Proporcionar apoio: ações, idéias e sentimentos. - Confiabilidade e lealdade: defender um amigo, apoiar seus direitos. Ensinar cada um a valorizar-se e apreciar seu próprio caráter. - Nas interações, os enfrentamentos, as negociações nas resoluções de conflitos desenvolvem segurança e maturidade para expor queixas, sentimentos e diferenças de opinião. - Ensinar as habilidades para fazer amigos: troca de papéis, treinamento e discussões em pequenos grupos. - Apoio social para a realização do aluno: os alunos aprendem mais em um ambiente que demonstre apoio, cooperação e encorajamento, em que todos são bem-vindos, do que em um ambiente de competição e exclusão. Todos os alunos beneficiam-se quando proporcionam apoio a outros colegas. - Consciência de amizade e respeito à diversidade: quando a proximidade física e as interações sociais se estabelecem, pode ser útil promover uma consciência da importância das amizades para todos os alunos.

Por fim, precisamos considerar que as diferenças não são excludentes. São complementares. Isto significa que é hora de termos menos informação e mais capacidade de organização do conhecimento. Já se abre o caminho para produzirmos menos gordura e mais flexibilidade, menos sedentarismo e mais movimento, mais trocas afetivas, menos pressa e mais vagar na grandeza de cada instante e no valor sem igual de cada um, menos economia e mais antropologia, menos competitividade, menos exclusão, menos classificação do outro, menos comparação, mais cooperação, mais valorização de cada um e mais formação e capacitação, menos repetição mecanicista e mais leitura da história e das próprias pessoas.

É preciso recuperar o conhecimento perdido na mera informação, na grande superficialidade pela qual navegamos quase como autômatos. É preciso desenvolver a qualidade mental de organizar e dominar o conhecimento em meio à multiplicidade de notícias produzidas e lançadas para todos os lados todos os dias. Este projeto requer de nós uma tarefa essencial, a de definir os rumos de nossa existência, de nosso trabalho, de nossa formação, os rumos de nossa docência escolar e não escolar, profissional e não profissional, selecionando sempre o considerado fundamental para nós, bem como os procedimentos, os caminhos para alcançá-lo, para que cada um manifeste sua aprendizagem segundo suas possibilidades e segundo sua condição humana. E se a condição humana é social, então a possibilidade é igualmente social, 
isto é, nasce do investimento radical na aprendizagem cooperativa, na organização de desafios e na garantia da manifestação da aprendizagem de cada um.

O conhecimento inclusivo é menos discursivo, menos fundado no princípio da separação. O conhecimento inclusivo é mais localizado nas necessidades reais das pessoas, portanto é cognitivo, fortemente afetivo-emocional, é artístico, motor e interativo.

\section{REFERÊNCIAS}

CECCIM, R. B. Exclusão e alteridade: de uma nota de imprensa a uma nota sobre deficiência mental. In: SKLIAR, C. Educação \& exclusão: abordagens sócio-antropológicas em educação especial. Porto Alegre: Mediação, 1997.

ILLAN, R. N. Educacion especial: pasado, presente y futuro. Murcia: Yerba, 1992.

PESSOTTI, I. Deficiência mental: da superstição à ciência. São Paulo: T. A. Queiroz, 1984.

Texto recebido em 21 fev. 2004

Texto aprovado em 24 abr. 2004 